
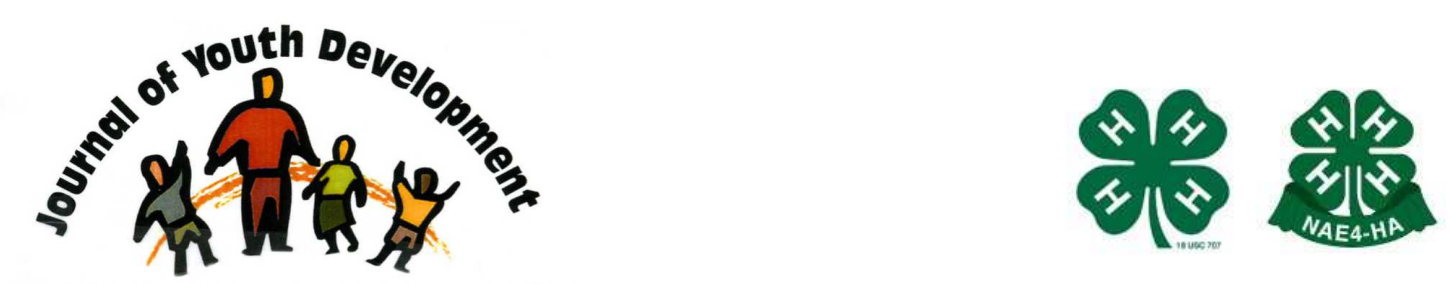

Bridging Research \& Practice

\title{
At-Risk Youth in After-School Programs: How Does \\ Their Use of Media for Learning About Community Issues Relate to Their Perceptions of Community Connectedness, Community Involvement, and Community Support?
}

\author{
Rosemary V. Barnett \\ Department of Family, Youth \& Community Sciences \\ University of Florida \\ Gainesville, FL \\ rbarnet@ufl.edu \\ Jeffrey C. Neely \\ College of Arts and Sciences \\ University of North Carolina Wilmington \\ Wilmington, NC \\ neelyj@uncw.edu \\ Caroline Payne-Purvis \\ Department of Family, Youth \& Community Sciences \\ University of Florida \\ Gainesville, FL \\ cmpayne@ufl.edu \\ Gerald R. Culen \\ Department of Family, Youth \& Community Sciences \\ University of Florida \\ Gainesville, FL \\ grculen@ufl.edu
}




\title{
JOURNAL OF YOUTH DEVELOPMENT \\ bridging research and practice

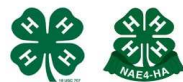

\section{At-Risk Youth in After-School Programs: How Does Their Use of Media for Learning About Community Issues Relate to Their Perceptions of Community Connectedness, Community Involvement, and Community Support?}

\author{
Rosemary V. Barnett, Caroline Payne-Purvis, Gerald R. Culen \\ University of Florida \\ Jeffrey C. Neely \\ University of North Carolina Wilmington
}

\begin{abstract}
This paper highlights a study examining the impact of various media formats on at-risk youth to identify forms of media technology that might impact their community connectedness, community involvement, and community support. Over a three-year period, a sample of 133 youth enrolled in after-school programs in two communities completed a questionnaire annually consisting of the following areas: community support, community involvement, community connectedness, and media use for learning. Linear regression analysis indicated media use for learning about community issues was a predictor of student's perceptions of community support, community connectedness, and community involvement. The media format most identified for gaining knowledge about community issues by the youth was the Internet, while the use of print media increased over the course of the study. The most significant relationships were found between media use and perceptions of community overall with the most significant gains in media use during $\mathrm{Y} 2$, where youth knowledge of community issues increased.
\end{abstract}

\section{Introduction}

Educating and involving youth in discussions about the issues facing their communities is important, not only for the long-term sustainability of the community, but also for effective, inclusive community-building efforts in the here and now. Historically in America, youth were integrally involved in their communities from the time of early settlement through the late $19^{\text {th }}$ 
century (Zeldin, Camino, \& Calvert, 2003). Young people worked side-by-side with their parents and other adults on farms and in mills and regularly interacted with adults at community celebrations and rituals. But with the advent of the industrial revolution and new labor laws, young people were soon shuffled into more formal educational paths and lost meaningful interaction that had previously come naturally with their communities. In turn, youth lost access to the social roles and networks essential to promoting their integration in the community.

In our contemporary society, developing effective youth-adult partnerships does not come without challenges (Camino, 2000). Envisioning youth as contributors and valuable assets in a community goes against the norms and trends that have developed over more than a hundred years. Bringing youth and adults together in the process of community-building defies the notion that youth need to be either protected or controlled. Many adults may find it difficult to accept youth as equal players in the community (Barnett, \& Brennan, 2006). Likewise, youth who desire to be involved in their communities may feel a lack of guidance and encouragement from adults and thus powerless to effect real change (Otis, 2006). However, the collective action of community members of all ages and backgrounds, where individuals are allowed to "participate in the creation, articulation, and implementation of efforts to support local change" creates a civic whole greater than the sum of its' parts (Barnett, \& Brennan, 2006). Including youth in positive community activities contributes to the development of the community, as well as to the social and psychological development of these young people. Moreover, when youth and adults work together, they develop greater mutual understanding and a shared sense of norms and values.

At-risk youth, those who are at increased risk for adversity, are presented with their own challenges in regard to connecting to their communities (Loughlin, Barnett, Culen, Stedman, \& Payne-Purvis, 2013). Often fraught with disorganization, youth residing in these communities are faced with the disjointedness of their ecology. Positive environmental supports may be scarce and, consequently, neighborhoods, typically safe places to grow up in, may not exist in their minds (Zeldin, \& Topitzes, 2002). It is an ironic aspect of life in the sense that those who need strong communities the most, experience them the least. Already faced with adversity, these youth are struggling to find the strength, security, and safety features normally found in local communities. Therefore, it is becoming increasingly more important to examine ways to improve their connections to their communities. Applying rigorous, scientific evidence-based practices to positive youth development efforts are essential for constructively connecting youth to their communities (Allison, Edmonds, Wilson, Pope, \& Farrell, 2011).

Media formats, including newspapers/magazines, Internet, books, TV, music, Social Networking, are one such way for youth to interact with their local community. When the infrastructure of community integration - the existing social networks and community ties - do not extend to certain people (e.g., youth), media can provide an alternative route for information and motivation (McLeod, Scheufele, \& Moy, 1999). Today's world provides many opportunities to use media, even for those in low SES areas. Local community centers, schools, and libraries provide access to the Internet and computers, TV, and movies. With respect to digital media, specifically, moderate Internet use is positively associated with maintaining real-world social ties (Wellman, Quan Haase, Witte, \& Hampton, 2001). Social networking sites such as Facebook, MySpace, and Twitter, which are particularly popular among youth, also offer opportunities to cross borders into areas outside of the immediate environment, opening up the world to those who seek it. At the same time, local libraries provide access to newspapers, magazines, books, movies, and music that can be free for those who cannot afford it. 


\section{Background to the Study}

When considering which factors make up a vibrant, thriving community and which factors contribute to positive community development, scholars have appealed to theoretical constructs such as: community attachment, community integration, community-building, resource mobilization, and civic engagement. While these perspectives tend to have significant overlap, the concept of community attachment carries with it a distinct and unique focus on the internal psychological process of individuals as they experience feelings of connectedness to their community. Specifically, this study explores youth and their relationship to community support, community involvement, and community connectedness.

In contrast, concepts like community integration, community-building, and civic engagement carry with them a dimension of active physical involvement in community processes and events. According to Weil (1996), "community building refers to activities, practices and policies that support and foster positive connections among individuals, groups, organizations, neighborhoods, and geographic and functional communities" (p. 482). In order to build community, it is not enough to simply care about or feel connected to the people that share local life experiences. Action is required for an individual (youth) to strengthen interpersonal community bonds along with places, events, and cultural products in which shared life experiences exist. However, one of the most powerful and effective ways for individuals to become motivated to take voluntary action in building their community is for them to have a personal emotional investment in it.

When individuals are connected or attached to their community, they will be more likely to become involved in building it. Attachment and a sense of community manifest themselves behaviorally through participation (Manzo, \& Perkins, 2006). Positive personal bonds of attachment and a sense of community among residents can be an important means of strengthening efforts to improve both the physical environments and social relationships in a community (Brown, Perkins, \& Brown, 2003). Beggs, Hurlbert and Haines (1996) proposed, "understanding the mechanisms of community attachment may be a step toward building a base of citizens who will work to foster community development" (p. 424).

The health of any functioning society or community is dependent upon successfully transmitting collective values from one generation to the next (John Dewey, 1916/2005). It is through communication that a community's ideals, hopes, expectations, standards, and opinions are passed from generation to generation. Communication ties generations together and ties individuals to the community.

The purpose of this study was to examine data from the United States Department of Agriculture (USDA) Children, Youth, and Families at Risk (CYFAR) Youth Involved in Community Issues project in order to understand how various formats of media provide knowledge to youth that may link them to community supports, community involvement, and community connectedness. By examining youth perceptions of where their knowledge comes from in regard to community issues (such as crime, recycling, unemployment, safety, drugs, etc.), we can consider the use of specific media formats to further connect youth who may be very disconnected from their communities.

Research questions included:

- Which forms of media do youth report most of their knowledge about community issues comes from? 
- Does the relationship between media use for knowledge of community issues and community variables (involvement, support and connectedness) change by program year?

- Are youth perceptions of community connectedness, involvement, and/or support related to the type of media format used for knowledge gains?

\section{Method}

\section{Data Collection}

The sample population for this study consisted of 133 at-risk youth enrolled in free after-school programs within their community that were provided by the USDA CYFAR project Youth Involved in Community Issues. Project sites were located in two counties in Florida - Seminole and Volusia. The project has been ongoing since 2009 and will be completed in summer 2014. The data were collected over a three year period in two rural communities where the project delivered free after school programs.

Prior to data collection, parents signed consent forms for all students participating in the CYFAR afterschool program. Data collection took place at the end of each academic school year (May/June) over multiple days. A total of 163 surveys were completed by the 133 participants during the three-year data collection period. Table 1 indicates the number of participants per county enrolled in after school programs during each year, as well as the number of retained participants from previous years as indicated in parentheses.

Table 1

Participant by Year and County

\begin{tabular}{|l|l|l|l|}
\hline & $\begin{array}{l}\text { Seminole County } \\
\text { (retained) }\end{array}$ & Volusia County (retained) & Total \\
\hline Year 1 (2009) & 18 & 9 & 27 \\
\hline Year 2 (2010) & $49(8)$ & $16(4)$ & $65(12)$ \\
\hline Year 3 (2011) & $58(16)$ & $13(8)$ & $71(24)$ \\
\hline Total & $125(24)$ & $38(12)$ & $163(36)^{*}$ \\
\hline
\end{tabular}

*36 participants were retained from $\mathrm{Y} 1$ to $\mathrm{Y} 3$. As a result these 36 individuals were only counted once in the total sample size to prevent participants being counted multiple times.

Informed consents, to explain the survey procedures, were presented to each participant and read aloud prior to data collection. Paper copies of the surveys were provided to students in small groups to allow for privacy while completing the surveys. Each survey contained an identification number and student's names were collected separate from the surveys to ensure parental consent had been obtained. No identifying information was placed on the surveys. For students with difficulty reading, survey administrators were available to assist. Students were encouraged to ask questions regarding the survey in order to respond as honestly as possible. The afterschool staff members were not present for the data collection and students were assured that the staff would not see individual responses to ensure confidentiality. Survey administrators reviewed each survey upon completion to ensure all items had been answered or initially omitted. Of the 165 completed questionnaires, 163 were used in the data analysis. Two individuals completed surveys in Y3 and were excluded because they were no 
longer within the desired school age range (i.e. they were in college and no longer in high school). Both participants previously completed the surveys in Y2, these data were retained. All other participants were included in the data analysis for a total of 163 surveys completed.

\section{Instrumentation}

Using the instrument, Youth Involvement in Community Issues (YICI), subscales of larger indices were used to examine youth's perception of community support, community involvement, and community connectedness. Each subscale consists of five individual items. The subscale of Community Support includes the items: I feel supported by my community, My community cares about me; Adult leaders in my community are concerned about my needs, Adults in my community are my role models, and There are adults I can talk to in my community.

The subscale of Community Involvement includes the items: Youth are very involved in the local community, I am very involved in my community, I would like to be more involved in my community; I am very motivated to be involved in my community, and I feel valued by my community as a result of my community involvement.

Finally, the subscale of Community Connectedness includes the items: Youth in my community have a voice; I feel connected to my community; I am not interested in what goes on in my community, I am able to influence decisions that affect my community, and I do not feel I have a positive impact on my community.

The YICI instrument also examines what types of media format youth perceive that they gain knowledge from relating to community issues. One additional YICI subscale examines possible media formats used by youth to learn about community issues. Youth were asked to indicate on a scale of strongly disagree (1) to strongly agree (5) in regard to which media formats I learn about community issues from: (Newspapers/Magazines, Books, TV, Movies, Music, Social Networking Websites, and the Internet).

Data were collected annually at the end of every school year and entered into individual spreadsheets for each year and each county. Data were then combined into one spreadsheet for all previous years for both counties. Because of the large amount of turnover in the afterschool program enrollment each year, this research examines responses for total project enrollment by year. Some students may have returned from one year to the next, however, this was more often not the case. Therefore, the analysis does not attempt to match individual responses; rather, it is considering whether there were changes in group responses for those youth participants in the annual after-school programs included in the project.

\section{Analysis}

Data were analyzed to examine the relationship between media formats as a means of gaining youth community knowledge and individual perceptions of community connectedness, community involvement, and community support. Descriptive statistics were conducted to examine demographic data (sex, race/ethnicity, age, grade in school). One-Way ANOVA, bivariate correlations and linear regressions were conducted to examine the mean differences, relationship between the independent (formats of media for knowledge regarding community issues) and dependent variables (community support, community connectedness, and community support), and the predictor variable of media use. 


\section{Results}

\section{Participants}

Participants ranged in age from 11 to 19 years, with a mean age of 13.26 (1.851). Of the participants, $50.3 \%$ (82) are females, $49.7 \%$ (81) are males; $73.0 \%$ indicated that their race is African American, $16 \%$ are Hispanic, $8.6 \%$ are White and $2.4 \%$ indicated Other. All participants were in middle or high school $\left(6^{\text {th }}-12^{\text {th }}\right.$ grade) with a majority of participants reporting that they are in middle school (65.6\%). County 1 students made up a majority of the sample population $76.1 \%$ (124); County 2 had 39 participants (23.9\%).

\section{Media and Community Variables}

Mean scores were computed using the scale of strongly disagree (1) to strongly agree (5). The mean scores indicate the extent to which students agree they learn about community issues from the various forms of media. Year one, two, and three mean scores for each of the subscales are indicated in Table 2. Overall media includes all seven forms of media examined within the index. Mean scores for overall media increased from Y1-Y2 (3.0476 to 3.5288) but decreased Y2-Y3 (3.5288 to 3.4391). Mean scores for overall media from Y1-Y3 saw an increase (3.0476 to 3.4391). Mean scores for each individual item by year can be found in Table 3. Significant differences in mean scores were found from $Y 1$ to $Y 2$ within TV $(f=6.526$, $p=.012)$. From $Y 2$ to $Y 3$ there were not significant differences in mean scores. Significant mean scores differences from $Y 1$ to $Y 3$ were found between Newspaper $(f=4.503, p=.036)$ and TV $(f=4.493, p=.037)$. During all three years, participants agreed most frequently that they learned about community issues from the Internet, Y1 62.9\%, Y2 76.2\% Y3 76.4\%.

Table 2

Mean Scores - Overall Totals for Media and Community Variables

\begin{tabular}{|l|l|c|l|c|}
\hline & Media & Connectedness & Involvement & Support \\
\hline $\mathrm{Y} 1 \mathrm{n}=27$ & $3.0476(1.24)$ & $2.9519(.93)$ & $3.0370(1.12)$ & $3.10(.97)$ \\
\hline $\mathrm{Y} 2 \mathrm{n}=65$ & $3.5288(1.01)$ & $3.4627(.69)$ & $3.6273(.93)$ & $3.8182(.85)$ \\
\hline $\mathrm{Y} 3 \mathrm{n}=71$ & $3.4391(1.03)$ & $3.4240(.73)$ & $3.2588(.91)$ & $3.4794(.92)$ \\
\hline
\end{tabular}

Table 3

Mean Scores - Overall Totals for Media and Community Variables

\begin{tabular}{|l|l|l|l|l|l|l|l|}
\hline & $\begin{array}{l}\text { Newspaper/ } \\
\text { Magazines }\end{array}$ & Books & TV & Movies & Music & $\begin{array}{l}\text { Social } \\
\text { Networking }\end{array}$ & Internet \\
\hline Y1 $\mathrm{n}=27$ & $\begin{array}{l}2.78 \\
(1.476)\end{array}$ & $\begin{array}{l}2.70 \\
(1.436)\end{array}$ & $\begin{array}{l}3.11 \\
(1.502)\end{array}$ & $\begin{array}{l}3.00 \\
(1.359)\end{array}$ & $\begin{array}{l}3.00 \\
(1.414)\end{array}$ & $\begin{array}{l}3.22 \\
(1.528)\end{array}$ & $\begin{array}{l}3.52 \\
(1.451)\end{array}$ \\
\hline $\mathrm{Y} 2$ & 3.28 & $\mathbf{3 . 3 3}$ & $\mathbf{3 . 9 0}$ & $\mathbf{3 . 2 7}$ & $\mathbf{3 . 4 8}$ & $\mathbf{3 . 4 6}$ & 3.99 \\
$\mathrm{n}=65$ & $(1.475)$ & $\mathbf{( 1 . 4 9 1 )}$ & $\mathbf{( 1 . 2 8 1 )}$ & $\mathbf{( 1 . 4 8 3 )}$ & $\mathbf{( 1 . 3 8 6 )}$ & $\mathbf{( 1 . 4 2 8 )}$ & $(1.273)$ \\
\hline $\mathrm{Y3}$ & $\mathbf{3 . 4 6}$ & 3.21 & 3.76 & 3.15 & 3.09 & 3.37 & $\mathbf{4 . 0 4}$ \\
$\mathrm{n}=71$ & $\mathbf{( 1 . 3 7 6 )}$ & $(1.322)$ & $(1.294)$ & $(1.509)$ & $(1.494)$ & $(1.475)$ & $\mathbf{( 1 . 2 2 7 )}$ \\
\hline Overall & 3.27 & 3.17 & 3.71 & 3.17 & 3.23 & 3.38 & 3.93 \\
$\mathrm{n}=163$ & $(1.445)$ & $(1.421)$ & $(1.345)$ & $(1.468)$ & $(1.443)$ & $(1.458)$ & $(1.291)$ \\
\hline
\end{tabular}

Using the three community subscales, mean scores for overall media impact on youth perceptions of community connectedness, community involvement, and community support, 
were analyzed using One-Way ANOVA (Table 4). In Y1 there were no significant findings for mean score differences between media use and community involvement, support or connectedness. In $\mathrm{Y} 2$, the relationship between media and community involvement was positive with a p-value of .04 using a One-Way ANOVA. In Y3, statistically significant mean differences between media use and connectedness existed with a p-value of .003 using a One-Way ANOVA.

Table 4

One-Way ANOVA-Media Use and At-Risk Youth Perceptions of Community

\begin{tabular}{|l|c|c|c|}
\hline & Media/Connectedness & Media/ Involvement & Media/ Support \\
\hline $\mathrm{Y} 1$ & 1.564 & .697 & 1.674 \\
$\mathrm{n}=27$ & .222 & .743 & .210 \\
\hline $\mathrm{Y} 2$ & 1.650 & $1.882 *$ & 1.256 \\
$\mathrm{n}=65$ & .081 & .040 & .257 \\
\hline $\mathrm{Y3}$ & $2.643 * *$ & .1 .758 & 1.307 \\
$\mathrm{n}=71$ & .003 & .053 & .218 \\
\hline * $\mathrm{P}<.05, * \mathrm{P}<.001$ & \multicolumn{3}{|l}{} \\
\hline
\end{tabular}

In addition, bivariate correlations were conducted between overall media scores and the community subscales (Table 5). In Y1, there was a positive statistically significant relationship between media and community connectedness, media and community involvement, and media and community support when conducting bivariate correlations. In Y2, there were no statistically significant relationships between media and community connectedness, involvement, or support. In Y3, there was a positive relationship between media and community connectedness with a p-value of .028 .

Table 5

Bivariate Correlations - Overall Media Use and At-Risk Youth Perceptions of Community

\begin{tabular}{|l|c|c|c|}
\hline & Media/Connectedness & Media/ Involvement & Media/ Support \\
\hline $\mathrm{Y} 1$ & $.412^{*}$ & $.432^{*}$ & $.530^{* *}$ \\
$\mathrm{n}=27$ & .033 & .024 & .008 \\
\hline $\mathrm{Y} 2$ & -.066 & -.171 & -.046 \\
$\mathrm{n}=65$ & .596 & .169 & .713 \\
\hline $\mathrm{Y3}$ & $.267 *$ & .064 & .213 \\
$\mathrm{n}=71$ & .028 & .604 & .081 \\
\hline$* \mathrm{P}<.05, * \mathrm{P}<.001$ & \multicolumn{3}{|}{} \\
\hline
\end{tabular}

Based on the correlation results, linear regression analysis (Table 6) was conducted to examine whether the use of media formats to use for learning about community issues was predictive of community support, community involvement, or community connectedness. As shown in Table 6 , linear regression analysis indicated that learning about community issues from media formats overall was predictive of student's perceived community support $\beta=.214 t(156)=2.73, p=.007$ and community connectedness $\beta=.211 t(160)=2.729, p=.007$. Individual years were also examined. In $\mathrm{Y} 1$, all three community variables were predicted by learning about community issues from media formats: community connectedness $\beta=.412 t(25)=2.261, p=.033$; community involvement $\beta=.432 t(25)=2.346, p=.024$; community support $\beta=.530 t(22)$ 
$=2.931, p=.008$. In $Y 2$, no community variables were predicted by learning about community issues from media formats. During $Y 3$, community connectedness was predicted by learning about issues from media formats $\beta=.267 t(66)=2.251, p=.028$.

Table 6

Linear Regression - Media Use Predictive of Community Variables

\begin{tabular}{|l|c|c|c|}
\hline \multicolumn{1}{|c|}{ Variable } & B & SE B & $\beta$ \\
\hline Connectedness (Y1) & .039 & .137 & $.412^{*}$ \\
\hline Involvement (Y1) & .389 & .162 & $.432^{*}$ \\
\hline Support (Y1) & .407 & .139 & $.530^{* *}$ \\
\hline Connectedness (Y3) & .188 & .083 & $.267^{*}$ \\
\hline $\begin{array}{l}\text { Total Connectedness } \\
\text { (Y1-Y3) }\end{array}$ & .151 & .055 & $.211^{* *}$ \\
\hline $\begin{array}{l}\text { Total Support } \\
\text { (Y1-Y3) }\end{array}$ & .188 & .069 & $.214^{* *}$ \\
\hline$* \mathrm{P}<.05 * * \mathrm{P}<.01$ & & & \\
\hline
\end{tabular}

Based on the correlation results, linear regression analysis was conducted to examine whether the use of media formats to use for learning about community issues was predictive of community support, community involvement, or community connectedness. Linear regression analysis indicated that learning about community issues from media formats overall was predictive of student's perceived community support $\beta=.214 t(156)=2.73, p=.007$ and community connectedness $\beta=.211 t(160)=2.729, p=.007$. Individual years were also examined. In $\mathrm{Y} 1$, all three community variables were predicted by learning about community issues from media formats: community connectedness $\beta=.412 t(25)=2.261, p=.033$; community involvement $\beta=.432 t(25)=2.346, p=.024$; community support $\beta=.530 t$ (22) $=2.931, p=.008$. In $Y 2$, no community variables were predicted by learning about community issues from media formats. During Y3, community connectedness was predicted by learning about community issues from media formats $\beta=.267 t(66)=2.251 p=.028$.

\section{Discussion}

The purpose of this study was to explore the at-risk youth perceptions of media use as a means to gain knowledge about community issues. Specifically, the variables of community connectedness, community involvement, and community support were examined. Media use included various formats of media that were examined individually and overall to examine the relationship between media and learning about community for these youth. Questions included: Which forms of media do youth report most of their knowledge about community issues comes from? Does the relationship between media use for knowledge of community issues and community variables change by program year? Are youth perceptions of connectedness, involvement, and/or support related to the type of media format used for knowledge gains?

An examination of individual media formats indicates that Internet use increased over time during the three-years of data collection (Table 3 ). It was also found to be the most often used format related to knowledge gains. This aligns with project goals to increase media use as a 
means to increase community involvement and connectedness. Youth were provided computers to use at the program sites and were provided designated time each week to access websites in order to increase knowledge regarding community issues. Specific projects were provided to youth to investigate their individual communities in an attempt to increase knowledge regarding issues present within their communities.

In response to the research question RQ1, the results suggest that the increase in overall Internet use among participants was due in large part to a specific increase in the use of online social networking. A Facebook group was established for each site and participants were informed of local leaders and agencies that had their own Facebook pages or Internet websites. The increased use of Internet as a media format is a positive indication that youth involved in this program gained technology skills over time. Since it is reported as the most used format to gain knowledge of community issues, this can be woven into curriculum lessons and activities for the project as well as for others working with at-risk participants in after-school programs. Y2 had significant increases in the use of media for community knowledge that also align with youth reports of increase positive perceptions of each of the community variables. Significant increases in five of the seven media formats between $Y 1$ and $Y 2$ indicate youth were using media formats of various types at increasing rates to learn about community through the program. Interestingly, the use of print media, such as newspapers and magazines, increased from $\mathrm{Y} 1-\mathrm{Y} 3$ and was significant in $\mathrm{Y} 3$, indicating that youth were reading more print media or had access to these types of materials through the program.

In response to RQ2, several statistically significant results emerged from the data analysis of atrisk youth perceptions of media formats and knowledge gains related to community connectedness, community involvement, and community support. First, from Y1 to Y2, there were gains in both media use for knowledge of community issues and youth's perception of all three community variables (Table 2). Throughout the program, youth were involved in community service projects in the local area which could possibly account for the increase in perceptions relating to community involvement. In addition, through the daily interaction with adult staff members, youth's perceptions of support from the community may have increased. Connectedness increased during this time, possibly as a result of this relationship that they had not experienced in other ways. Youth use of media formats and perceptions of community remained fairly stable between $\mathrm{Y} 2$ and $\mathrm{Y} 3$ with a slight decrease in all four variables, indicating that as the program continued, youth had settled in to the topics of community issues and their use of media likewise remained consistent. Further, there were staff changes during Y2 that may account for the changes in media use during the transition.

With each year of the after-school program, the relationship between media use and knowledge of community issues increased. There was not a significant relationship in $Y 1$. In $Y 2$, it became a positive relationship, and in $\mathrm{Y} 3$ it became a strong positive relationship (Table 4). This supports project staff efforts to utilize media to increase knowledge of community, increase participant perceptions of community support and involvement, as well as, have important community connections made. This is very important for these youth, who are in low SES neighborhoods, and that may not have opportunities to see other parts of their local area. Connectedness came out the strongest of the three community variables in regard to explaining the variation of means, indicating that important connections were being made by youth. Connecting them to community builds pride and attachment, which can help protect them from risk factors and increase their resiliency (Loughlin, et al., 2013). 
There was an overall relationship between media use for knowledge gains of community issues that was found to be positive across all three community variables in Y1; not found in Y2; and found again to be positive in Y3 with community connectedness (See Table 5). It is uncertain why it was not found in Y2 as other analysis seemed to indicate that media use during Y2 was significant; however, as previously discussed, it was more significant with some media formats than others. This indicates that even though media use overall was not always found to be positively related to the community variables, certain types of media were perceived by youth to be instrumental in learning about community.

Last, media use for knowledge gains was found to be a predictor of all community variables in Y1. This is explained by their recent exposure to media through the after-school program that may have provided access to certain forms of media for the first time. Youth reported in Y1 that they did not have Internet access at home $(0 \%)$, therefore, they were eager to utilize the media formats made available to them. Further, it was predictive of community connectedness in Y3 showing indications that youth were learning via media how to connect to community. Media use was also a predictor for total support across all three years. During this time, youth were engaged in using social networking sites to explore community groups, leaders, agencies and organizations. Finally, total connectedness to community was predicted by media use over all three years. These results indicate that there is a strong predictive relationship between media use and the community variables examined.

The overall analysis enlightened our understanding of the media formats shaping learning behaviors for community issues. Respondents across the three years reported that media played an important role in their learning process. This allows project staff to consider further how to integrate media use into project activities, lessons, and communication. It also helps staff identify which technology youth perceive as most related to their perceptions of community supports, involvement and connectedness.

\section{Conclusion}

While the results of this study provide interesting insights into the relationship between at-risk youth, media, and community, further research should build from these results to more clearly examine these relationships. In particular, research is essential to determine the media formats that students identify for the most knowledge gains relating to community issues. Based on their media preferences, project staff could redirect them toward the media formats to increase learning in the informal setting of an after-school program.

The relationship between media format and learning about community issues exists and is strong. Further, these results indicate the importance of media use to educate youth regarding issues within communities, as this is predictive of their perception of community support, involvement and connectedness. These three variables are fundamental to the growth and development of adolescents and the communities in which they reside. A further understanding of media and how it can be used specifically for at-risk youth to maximize learning about specific community topics is important, as well as determining how the more abstract concepts and perceptions of community attachment of youth may relate to media use as a means for strengthening it. 


\section{References}

Allison, K.W., Edmonds, T., Wilson, K., Pope, M., \& Farrell, A.D. (2011). Connecting youth violence prevention, positive youth development, and community mobilization. American Journal of Community Psychology, 48, 8-20.

Barnett, R. \& Brennan, M.A. (2006). Integrating youth into community development: Implications for policy planning and program evaluation. Journal of Youth Development, 1(14). Retrieved March 17, 2009, from http://www.nae4ha.org/directory/jyd/showdoc.aspx?id=bfae4d72-edae-4d6f-b7edd5316d66f6ef

Beggs, J.J., Hurlbert, J.S., \& Haines, V.A. (1996). Community attachment in a rural setting: A refinement and empirical test of the systemic model. Rural Sociology, 61(3), 407-426.

Brown, B.B., Perkins, D., \& Brown, G. (2003). Place attachment in a revitalizing neighborhood: Individual and block levels of analysis. Journal of Environmental Psychology, 23: 259 -271.

Camino, L.A. (2000). Youth-adult partnerships: Entering new territory in community work and research. Applied Developmental Science, 4(1), 11-20.

Dewey, J. (2005). Democracy and education. New York: Cosmo Classics. (Original work published 1916.

Loughlin, T., Barnett, R.V., Culen, G.R., Stedman, N.L.P., Payne-Purvis, C. (2013). Self-esteem and feelings of community connectedness of at-risk adolescents attending community-based after-school programs. Journal of Youth Development. (In press).

Manzo, L.C., \& Perkins, D.D. (2006). Finding common ground: The importance of place attachment to community participation and planning. Journal of Planning Literature, 20(4), 335350.

McLeod, J.M., Scheufele, D.A., \& Moy, P. (1999). Community, communication, and participation: The role of mass media and interpersonal discussion in local political participation. Political Communication, 16, 315-336.

Otis, M.D. (2006). Youth as engaged citizens and community change advocates through the Lexington Youth Leadership Academy. In B.N. Checkoway \& L.M. Gutierrez (Eds.), Youth participation and community change (pp. 71-88). New York: Haworth Press.

Weil, M.O. (1996). Community building: Building community practice. Social Work, 41(5), 481499.

Wellman, B., Quan Haase, A., Witte, J., \& Hampton, K. (2001). Does the Internet increase, decrease, or supplement social capital?: Social networks, participation, and community commitment. American Behavioral Scientist, 45(3), 436-455.

Zeldin, S., Camino, L., \& Calvert, M. (2003). Toward an understanding of youth in community governance: Policy priorities and research directions. Análise Psicológica, 25(1), 77-95. 
Zeldin, S., \& Topitzes, D. (2002). Neighborhood experiences, community connection, and positive beliefs about adolescents among urban adults and youth. Journal of Community Psychology, 30(6), 647-669.

(c) Copyright of Journal of Youth Development $~$ Bridging Research and Practice. Content may not be copied or emailed to multiple sites or posted to a listserv without copyright holder's express written permission. Contact Editor at: patricia.dawson@oregonstate.edu for details. However, users may print, download or email articles for individual use.

ISSN 2325-4009 (Print); ISSN 2325-4017 (Online) 